\title{
Food allergies in rural areas
}

\author{
Monika Stoma ${ }^{1}$, Beata Ślaska-Grzywna², Wioletta A. Żukiewicz-Sobczak³, Małgorzata Kostecka4, \\ Monika Bojanowska ${ }^{4}$, Agnieszka Dudziak ${ }^{1}$, Agnieszka Kuna-Broniowska², Piotr Adamczuk ${ }^{5}$, Paweł Sobczak , \\ Dariusz Andrejko²
}

\author{
'Department of Power Engineering and Transportation, Subdepartment of Logistics and Business Management, \\ University of Life Sciences, Lublin, Poland \\ ${ }^{2}$ Department of Biological Bases of Food and Feed Technologies, University of Life Sciences, Lublin, Poland \\ ${ }^{3}$ Department of Health, Regional Center Research of Environment, Agriculture and Innowvative Technology EKO-AGRO-TECH, \\ Pope John Paul II State School of Higher Education, Biala Podlaska, Poland \\ ${ }^{4}$ Department of Chemistry, Faculty of Food Science and Biotechnology, University of Life Science, Lublin, Poland \\ ${ }^{5}$ Institute of Rural Health, Lublin, Poland \\ ${ }^{6}$ Department of Food Engineering and Machines, University of Life Science, Lublin, Poland
}

Adv Dermatol Allergol 2016; XXXIII (4): 281-285

DOI: $10.5114 /$ ada.2016.61604

\begin{abstract}
Introduction: A food allergy is a group of symptoms occurring in the organism and resulting from consuming some food, where the problems are conditioned by immunological mechanisms. The symptoms may become apparent first in adulthood and they may be an initial manifestation of a latent allergy. Typical symptoms of a food allergy occur in different organs, thus not only in the digestive system, but also in the skin, respiratory system and circulatory system.

Aim: To assess the frequency of food allergy onset in rural areas of the Lublin region as well as to determine which factors induce such allergies.

Material and methods: A survey was conducted, involving the participation of 340 inhabitants of rural areas. The study monitored the knowledge and situation of the disease, concerning allergens, allergy symptoms, methods of treatment and opinions regarding such treatment.

Results: The analysis focused on 124 people with diagnosed allergies.

Conclusions: Introducing a diet did not result in a statistically significant difference regarding elimination of the symptoms, as compared to the patients who did not follow any diet. On the other hand, pharmacological treatment causes statistically worse results than using other methods or not being treated at all. The patients in whom allergy symptoms disappeared were more convinced about the positive character of their diet than those in whom the symptoms were not eliminated. The age when the allergy becomes evident does not affect its duration, yet it matters as to the time of its later elimination. The more symptoms were experienced by a patient, the longer the duration of the allergy was.
\end{abstract}

Key words: food allergy, survey analyses.

\section{Introduction}

It has been observed during the recent decades that there has been an increase in the frequency of diagnosing food allergies in adult patients and children. It is supposed that this phenomenon may be related to an increase in the onset of other allergic diseases (asthma, atopic dermatitis, allergic rhinitis), considering the fact that food allergy is typically the first clinical manifestation of these diseases, occurring in childhood [1, 2]. This is an interdisciplinary problem since symptoms and disorders having a cause-and-effect relationship with consuming different food products make people look for help with doctors representing different specializations.

Epidemiological studies conducted so far assess the frequency of food allergies at ca. $4 \%$ of the whole population (220-250 million people all over the world may suffer from food allergies), irrespective of their age [3]. An increase in the occurrence of allergies was also noted in developing countries, which is, as revealed by studies

Address for correspondence: Wioletta A. Żukiewicz-Sobczak HSc, PhD, Prof., Pope John Paul II State School of Higher Education, 95/97 Sidorska St, 21-500 Biala Podlaska, Poland, fax: +48 6981437 43, e-mail: wiola.zukiewiczsobczak@gmail.com Received: 25.05.2015, accepted: 3.07.2015. 
related to the civilization progress, related to changes in the traditional lifestyle and nutrition [4]. According to the data quoted by the ECAP program (the Epidemiology of Allergic Diseases in Poland) from 2008 which involved nearly 23,000 Poles, the incidence of allergic symptoms is more frequent in cities than in rural areas. This is associated primarily with the environmental pollution and different lifestyle.

The most frequent cause of oversensitivity and clinical symptoms among allergic children and adults is "the big eight food allergens" recognized by the World Health Organization. The potential number of allergenic foods is however much higher, there are more than 160 of them.

On the basis of studies and meta-analyses from 20002012 it is possible to determine the incidence of allergies in the European population, induced by cow milk, eggs, wheat, soy, peanuts, tree nuts, fish and shellfish at the level of: $6.0 \%$ (95\% confidence intervals: $5.7-6.4), 2.5 \%$ (2.3-2.7), 3.6\% (3.0-4.2), 0.4\% (0.3-0.6), 1.3\% (1.2-1.5), $2.2 \%(1.8-2.5)$ and $1.3 \%(0.9-1.7)$. Allergies to cow milk and eggs were most common among younger children, while allergies to peanuts, tree nuts, fish and shellfish were definitely more frequent among adult patients [5].

Studies on the incidence of allergies to milk in rural areas revealed that consumption of unpasteurized milk by children living in rural areas was an agent reducing the occurrence of IgE-dependent hypersensitivity in comparison to children living in urban areas who were drinking pasteurized milk [6]. Similar results were recorded by Dimich-Ward et al. who demonstrated that rural conditions may become a factor reducing the incidence of asthma and allergic rhinitis, as compared with the urban population [7]. On the other hand, Lampi et al. demonstrated that regular contact with livestock may be an agent reducing the probability of getting asthma and other allergic diseases in adulthood [8].

\section{Aim}

The aim of the present study was to assess the incidence of food allergies in rural areas of the Lublin region and to determine factors inducing allergies as well as to determine the frequency of co-incidence of other types of allergies.

\section{Material and methods}

The survey included 340 individuals, 140 male and 199 female (1 person did not mark their sex). Among the respondents there were 214 individuals with no allergies, and one person was not sure (answered "I don't know"). The remaining 96 individuals admitted suffering from an allergy and 28 people stated an allergy diagnosed in their children and completed the questionnaire for them. Further analysis will concern the 124 individuals who are allergic themselves.
These included 46 males, 77 females and 1 person who did not determine their sex; this means that allergies were experienced by $32.86 \%$ of the male respondents and by $38.69 \%$ of the female patients.

Among the allergic individuals, 8.9\% (11 people) were under $18,46.8 \%$ (58 people) were aged $19-25,21 \%$ (26 people) were $26-35$ years old, $20.2 \%$ (25 people) were aged $36-55$, and $2.4 \%$ (3 people) were 56 or more years old. One person did not give their age.

The questionnaire was composed of questions about personal experience concerning the allergy, opinions about the allergy and its treatment and sociodemographic situation.

\section{Statistical analysis}

The data were analyzed using the IMB SPSS Statistics program, version 21. The basic statistics, such as frequencies, were calculated for all items; means and standard deviations for the quantitative ones. The coefficients of Pearson's correlation in pairs were calculated in order to check the relations between some quantitative variables (age of appearance of an allergy; age when symptoms disappeared for those who had recovered; number of products to which individual people are allergic; number of symptom types experienced; number of allergens). The hypotheses concerning the methods of treatment and its results were verified using $t$-Student test for independent samples and $\chi^{2}$ test, depending on the type of data. The $\chi^{2}$ tests were applied for dichotomous variables (whether the treating of an allergy was effective or not; whether the person was dieting or not; whether the person was using a particular method of treatment or not). $t$-Student test for independent samples was used for some quantitative or quasi-quantitative data (number of treatments applied; opinions about allergy answered on a 5-degree Likert's scale).

\section{Results}

The most allergenic products were cow milk, strawberries, nuts and citrus fruits (Table 1).

Among the individuals listing allergenic products, half of the people (50\%) were allergic to only one product on the list (Table 1). Six individuals did not know what had caused their allergies, and the remaining people were allergic to more than one product on the list. The maximum number of allergenic products ticked was six (Table 2).

\section{Symptoms}

The majority of respondents (66.13\%) stated that they were experiencing skin problems, next there were disorders of the digestive system (36.29\%) and respiratory system (32.26\%). The anaphylactic shock and other symptoms are rare in the case of food allergies. The data found in the literature of the subject also suggest their rare incidence, yet the incidence of anaphylaxis induced 
Table 1. Comparison of food products to which the respondents became most frequently allergic

\begin{tabular}{lcc}
\hline Allergen & Allergic individuals (\%) & Number of people \\
\hline Cow milk & 40.3 & 50 \\
\hline Nuts & 25.8 & 32 \\
\hline Strawberries & 25.8 & 32 \\
\hline Citrus fruits & 25.8 & 32 \\
\hline Chicken eggs & 19.4 & 24 \\
\hline Chocolate & 17.7 & 22 \\
\hline Other & 16.1 & 20 \\
\hline Cheese & 13.7 & 17 \\
\hline Cereals & 10.5 & 13 \\
\hline Red meat & 3.2 & 4 \\
\hline Fish & 2.4 & 3 \\
\hline Shellfish & 2.4 & 3 \\
\hline Poultry & 1.6 & 2
\end{tabular}

The percent added dos not sum up to $100 \%$ because it was possible to choose more than one allergen.

by food differs depending on the region and dietary habits of a given population. In the USA it is estimated at ca. 10.8 cases per 100,000 individuals annually. Similar data are quoted for Great Britain and France. According to studies conducted in Denmark, the incidence of anaphylactic reaction after consuming food products in this country amounts to 3.2 cases per 100,000 inhabitants annually, with the death rate at ca. $5 \%$. Allergies to food are the cause of more than a half of serious anaphylactic reactions in Italian children treated in intensive therapy wards and they account for $1 / 3$ to $1 / 2$ of anaphylaxes treated in Intensive Therapy wards in North America, Europe and Australia $[9,10]$. The majority of respondents (60.5\%) declared that they had experienced only one of previously mentioned symptoms, while $29 \%$ experienced two types of symptoms.

We confirmed the hypothesis saying that the more products a given individual is allergic to, the higher probability that they will experience more than a single symptom of the allergy. The correlation between the number of products to which individual people are allergic and the number of symptom types experienced is 0.315 and is statistically significant $(p<0.001)$. This means that many people react to individual products in a varied way, rather than typically.

\section{Treatment}

Among 124 allergic patients, 51 (41.13\%) individuals declared that the symptoms had resolved, while 73 people are still suffering from allergies (Table 3 ).
Table 2. Number of allergens harmful to the respondents

\begin{tabular}{ccccc}
\hline Valid & Frequency & Percentage & $\begin{array}{c}\text { Percentage } \\
\text { valid }\end{array}$ & $\begin{array}{c}\text { Cumulative } \\
\text { percentage }\end{array}$ \\
\hline 0.00 & 6 & 4.8 & 4.8 & 4.8 \\
\hline 1.00 & 62 & 50.0 & 50.0 & 54.8 \\
\hline 2.00 & 16 & 12.9 & 12.9 & 67.7 \\
\hline 3.00 & 17 & 13.7 & 13.7 & 81.5 \\
\hline 4.00 & 10 & 8.1 & 8.1 & 89.5 \\
\hline 5.00 & 9 & 7.3 & 7.3 & 96.8 \\
\hline 6.00 & 4 & 3.2 & 3.2 & 100.0 \\
\hline Total & 124 & 100.0 & 100.0 & \\
\hline
\end{tabular}

The most popular treatment of a food allergy is the elimination diet and desensitization (Table 4). Twentyseven individuals did not undergo any treatment. Interestingly, in 9 out the 27 people who did not have any treatment, the symptoms resolved spontaneously.

The $\chi^{2}$ tests checking if a particular method of treating an allergy was effective revealed that none of the methods resulted in a significant difference between people applying it as compared with the results of individuals who did not diet (they chose a different method or did not have any treatment at all). Only in the case of pharmacological treatment there is a statistically significant difference, though the test demonstrates that this is the least effective method. Among 28 individuals undertaking this type of treatment, only 6 patients noted expected results. Pharmacological treatment causes statistically worse results, as compared with using other methods or giving up any treatment at all. The reason may be the fact that the individuals taking medicines believe in their power so much that they neglect dietary restrictions and become more susceptible to allergens than the remaining people. The results of the test for independence of two variables, $\chi^{2}$, are statistically significant, which let us adopt a hypothesis about a relevant relationship between the analyzed variables of introducing pharmacological treatment and eliminating the symptoms of allergies, $\chi^{2}(1, n=124)=5.797 ; p<0.05$. However, the relationship is too weak and the contin-

Table 3. Elimination of symptoms following pharmacological treatment

\begin{tabular}{lcccc}
\hline Variable & \multicolumn{3}{c}{$\begin{array}{c}\text { Pharmacological } \\
\text { treatment }\end{array}$} & Total \\
\cline { 2 - 4 } & & No & Yes & \\
\hline $\begin{array}{l}\text { Did the symptoms } \\
\text { disappear? }\end{array}$ & No & 51 & 22 & 73 \\
\cline { 2 - 4 } & Yes & 45 & 6 & 51 \\
\hline Total & & 96 & 28 & 124 \\
\hline
\end{tabular}


M. Stoma, B. Ślaska-Grzywna, W.A. Żukiewicz-Sobczak, M. Kostecka, M. Bojanowska, A. Dudziak, A. Kuna-Broniowska, P. Adamczuk, P. Sobczak, D. Andrejko

Table 4. Methods of treatment used by the respondents

\begin{tabular}{lcc}
\hline Method of treatment & $\begin{array}{c}\text { People using } \\
\text { the method } \\
\text { of treatment (\%) }\end{array}$ & $\begin{array}{c}\text { Number } \\
\text { of people }\end{array}$ \\
\hline Elimination diet & 53.23 & 66 \\
\hline Desensitized & 37.90 & 47 \\
\hline $\begin{array}{l}\text { Pharmacologically } \\
\text { treated }\end{array}$ & 22.58 & 28 \\
\hline No treatment & 21.77 & 27 \\
\hline Homeopathy & 4.84 & 6 \\
\hline Bioresonance & 2.42 & 3 \\
\hline Other methods & 2.42 & 3 \\
\hline
\end{tabular}

gency coefficient amounts to $0.216(p<0.05)$, the phi measure has the same value (with a negative symbol).

$41.9 \%$ of respondents used one method of treatment, while $36.2 \%$ said that they were using more than one method (Table 5). Hence, we compared the proportions of recovery between individuals who applied any method of treatment and those who did not take up any treatment at all (Table 6). It turned out that there was no statistically significant difference between these groups of allergic patients. However, since the study involved 27 individuals who were just allergic and did not take up any treatment, and in $1 / 3$ of them ( 9 people) allergy disappeared spontaneously, the sample may be too small to draw far-reaching conclusions.

While analyzing the questionnaire data related to food allergies, special attention should be paid to the issue whether improvement of the health condition may be achieved through the diet only, especially in the case of people complaining primarily of symptoms from the digestive system (Table 7). Among the 45 individuals experiencing such symptoms, being on a diet did not result

Table 6. Elimination of symptoms following any method of treatment

\begin{tabular}{lcccc}
\hline Variable & & \multicolumn{2}{c}{$\begin{array}{c}\text { Did the symptoms } \\
\text { disappear? }\end{array}$} & Total \\
\cline { 2 - 4 } & & No & Yes & \\
\hline $\begin{array}{l}\text { Did you use } \\
\begin{array}{l}\text { any method of } \\
\text { treatment? }\end{array}\end{array}$ & No & 18 & 9 & 27 \\
\cline { 2 - 4 } & Yes & 55 & 42 & 97 \\
\hline Total & & 73 & 51 & 124 \\
\hline
\end{tabular}

Table 5. Number of methods of treatment taken up by the respondents

\begin{tabular}{ccccc}
\hline Valid & Frequency & Percentage & $\begin{array}{c}\text { Percentage } \\
\text { valid }\end{array}$ & $\begin{array}{c}\text { Cumulative } \\
\text { percentage }\end{array}$ \\
\hline 0.00 & 27 & 21.8 & 21.8 & 21.8 \\
\hline 1.00 & 52 & 41.9 & 41.9 & 63.7 \\
\hline 2.00 & 37 & 29.8 & 29.8 & 93.5 \\
\hline 3.00 & 5 & 4.0 & 4.0 & 97.6 \\
\hline 4.00 & 3 & 2.4 & 2.4 & 100.0 \\
\hline Total & 124 & 100.0 & 100.0 & \\
\hline
\end{tabular}

in a statistically significant difference regarding elimination of the symptoms in comparison with people who were not dieting (yet they could use other methods of fighting their allergy).

It is worth considering why the elimination diet does not have higher efficiency in removing the symptoms of an allergy. The reasons may be as follows:

- non-rigorous dieting, which results in recurring symptoms,

- lack of awareness regarding the presence of the allergen in some other products as well,

- lack of awareness about being allergic to more products,

- adequate comprehension of the question - some people may understand "elimination of symptoms" as "I am not allergic any longer and I can eat anything", while some others may perceive it as "the symptoms are eliminated only when I'm dieting". In short, some people may understand "elimination of symptoms" as complete recovery, while for others it means temporary recovery from the allergy, which is also related to more or less rigorous dieting. If a person follows their diet, they will probably claim that "the symptoms have

Table 7. Elimination of symptoms following elimination diet

\begin{tabular}{lcccc}
\hline Variable & & \multicolumn{2}{c}{$\begin{array}{c}\text { Did the symptoms } \\
\text { disappear? }\end{array}$} & Total \\
\cline { 2 - 4 } & & No & Yes & \\
\hline \multirow{2}{*}{ Elimination diet } & No & 13 & 5 & 18 \\
\cline { 2 - 4 } & Yes & 17 & 10 & 27 \\
\hline Total & & 30 & 15 & 45 \\
\hline
\end{tabular}

Table 8. The onset of symptoms vs. age

\begin{tabular}{|c|c|c|c|c|c|}
\hline Variable & $\begin{array}{l}\text { Did the symptoms } \\
\text { disappear? }\end{array}$ & $N$ & Mean & $\begin{array}{l}\text { Standard } \\
\text { deviation }\end{array}$ & $\begin{array}{c}\text { Standard error, } \\
\text { mean }\end{array}$ \\
\hline \multirow{2}{*}{$\begin{array}{l}\text { At what age did the symptoms } \\
\text { appear? }\end{array}$} & Yes & 49 & 6.26 & 5.737 & 0.820 \\
\hline & No & 72 & 13.42 & 13.836 & 1.631 \\
\hline
\end{tabular}


disappeared", while someone who treats their diet in a more liberal way may conclude that "the symptoms have not been eliminated".

The age at which an allergy appears does not affect its duration, while it matters as far as its further elimination is concerned (Table 8). The individuals in whom the allergy disappeared, it had become apparent at the age of 6.26 on average (standard deviation: 5.73 years of age). The people who on the day of filling the questionnaire were still allergic had fallen ill much later, at the age of 13.42 on average, and the range of these values is in this case much wider (standard deviation: 13.84). This suggests that it may be easier to treat allergy during adolescence, as compared with later years.

The more symptoms the allergic person observed, the longer their allergy lasted (Pearson's correlation between the variables is positive and statistically relevant, $r=0.360, p<0.05)$. This may be related directly to the fact that a higher number of symptoms results from a larger number of products to which an individual is allergic; it takes more time to fight a complicated allergy.

As results from the above, it is also worth finding the relationship between the number of allergens and the duration of the allergy. Pearson's correlation between the variables is positive and statistically significant, $r=0.365$, $p<0.01$. The more allergens an individual was allergic to, the longer they were fighting their allergy.

\section{Views versus results}

Among the questions referring to the causes of the allergy and possibilities of its elimination, we chose the ones that regarded its active prevention:

- food allergies may be prevented or the risk of their acute course may be eliminated,

- thermal treatment of the majority of products reduces their allergenic properties,

- following rigorously a proper diet will significantly alleviate the course of a food allergy.

Responses to these questions (on a 5-degree Likert's scale, from "I completely disagree = 1" to "I absolutely agree $=5$ ") were summed up and then the mean value was calculated for these three questions for each individual person. The people in whom the symptoms of allergy disappeared were more convinced about the validity of the above statements ( $\mu=4.1 ; \sigma=0.56)$ in comparison to those in whom the symptoms did not disappear ( $\mu=3.11 ; \sigma=0.56$ ); the difference was statistically significant $t(121)=2.836, p<0.005$

However, it is hard to claim what the reason was and what the result was. Effective treatment could have filled some people with optimism and affected their opinions regarding man's influence on fighting allergies. Or, conversely, it could be the belief that allergy can be efficiently treated that helped the individuals fight it by following systematically the adequate diet or treatment.

\section{Conclusions}

The data from the questionnaire have provided the information on the basis of which it can be claimed that the elimination diet did not result in any statistically significant difference regarding the disappearance of symptoms, as compared with the individuals who did not go on such a diet.

The data also suggest that pharmacological treatment gives statistically worse results than using other methods or refusing to take up treatment. After using statistical tools, it can be also stated that the age when the allergy becomes apparent is irrelevant to its duration. The analysis of the data suggests that the age at which the allergy becomes apparent is important for its later elimination. A significant fact is also that the more symptoms were experienced by the allergic person, the longer the duration of the allergy was.

The individuals in whom the symptoms of the allergy disappeared were more convinced about validity of the dietary restrictions than those in whom the symptoms were not eliminated.

\section{Conflict of interest}

The authors declare no conflict of interest.

\section{References}

1. Hosking CS, Heine RG, Hill DJ. The Melbourne Milk Allergy Study - two decades of clinical research. Allergy Clin Immunol Int 2000; 12: 198-205.

2. Turner PJ, Pawankar R, Taylor S, et al. Precautionary labelling of foods for allergen content: are we ready for a global framework? World Allergy Organ J 2014; 7: 10.

3. White Book on Allergy 2011-2012. World Allergy Organization 2011.

4. Fogarty A. What have studies of non-industrialised countries told us about the cause of allergic disease? Clin Exp Allergy 2015; 45: 87-93.

5. Nwaru BI, Hickstein L, Panear SS, et al. EAACI Food Allergy and Anaphylaxis Guidelines Group. Prevalence of common food allergies in Europe: a systematic review and metaanalysis. Allergy 2014; 69: 992-1007.

6. Perkin MR, Strachan DP. Which aspects of the farming lifestyle explain the inverse association with childhood allergy? J Allergy Clin Immunol 2006; 117: 1374-81.

7. Dimich-Ward H, Chow Y, Chung J, Trask C. Contact with livestock: a protective effect against allergies and asthma? Clin Exp Allergy 2006; 36: 1122-9.

8. Lampi J, Canoy D, Jarvis D, et al. Farming environment and prevalence of atopy at age 31: prospective birth cohort study in Finland. Clin Exp Allergy 2011; 41: 987-93.

9. Bircher AJ, Van Melle G, Haller E, et al. IgE to food allergens are highly prevalent in patients allergic to pollens with and without symptoms of food allergy. Clin Exp Allergy 1994; 24: 367-74.

10. Caffarelli C, Deriu FM, Terzi V, et al. Gastrointestinal symptoms in patients with asthma. Arch Dis Child 2000; 82: 131-5. 